\section{Life-threatening hypokalaemia from abuse of Nurofen Plus}

\section{A Paul Lambert PhD Colin Close MD}

J R Soc Med 2005;98:21

Non-steroidal anti-inflammatory drugs are widely available as over-the-counter preparations. Adverse effects of these drugs include nephrotoxicity. ${ }^{1}$

\section{CASE HISTORY}

A woman aged 45 came to hospital in a drowsy state, with headache. For three months her mood had been low and she had been prescribed fluoxetine $20 \mathrm{mg} /$ day. She was thin (body mass index $17 \mathrm{~kg} / \mathrm{m}^{2}$ ) and normotensive. Investigations revealed a serum potassium of $2.6 \mathrm{mmol} / \mathrm{L}$ (reference range 3.5-5.0) and a serum creatinine of $56 \mu \mathrm{mol} / \mathrm{L}$ (60-120). She recovered spontaneously, but at discharge 48 hours later her potassium concentration had fallen to $2.8 \mathrm{mmol} / \mathrm{L}$. Six months before, serum potassium had been $4.5 \mathrm{mmol} / \mathrm{L}$. She had two further admissions in the next six weeks with drowsiness and general weakness, on each occasion with profound hypokalaemia (potassium 2.0 and $1.7 \mathrm{mmol} / \mathrm{L}$, respectively). On the third admission, further investigation revealed an arterial $\mathrm{pH}$ of 7.4 (7.357.45) with $\mathrm{pCO}_{2} 4.0 \mathrm{kPa}$ (4.5-6.1), serum bicarbonate $19 \mathrm{mmol} / \mathrm{L}(24-32)$ and chloride $110 \mathrm{mmol} / \mathrm{L}$ (96-105) (anion gap $18 \mathrm{mmol} / \mathrm{L}$ ). She had a normal serum magnesium, $0.9 \mathrm{mmol} / \mathrm{L}$ (0.7-1.0). Urine $\mathrm{pH}$ was 7.0 and $24 \mathrm{~h}$ urine potassium excretion was $120 \mathrm{mmol}$, giving a transtubular potassium gradient of $7.3 \mathrm{mmol} / \mathrm{L}$. Renal tubular acidosis with renal potassium wasting was diagnosed and she was treated with oral sodium bicarbonate $6 \mathrm{~g} /$ day and oral potassium $2.8 \mathrm{~g}(72 \mathrm{mmol})$ per day. Potassium rose to $4.3 \mathrm{mmol} / \mathrm{L}$ and bicarbonate to $29 \mathrm{mmol} / \mathrm{L}$.

A urine drug screen was positive for ibuprofen, paracetamol, opioids and benzodiazepines, and she was subsequently readmitted after self-poisoning with Nurofen Plus (ibuprofen $600 \mathrm{mg}$, codeine phosphate $12.8 \mathrm{mg}$; Crookes Healthcare Ltd, Nottingham, UK). From another source we learned that her flat was littered with empty Nurofen Plus packets, and she later described regularly consuming $28 \mathrm{~g} /$ day of ibuprofen.

Division of Medicine, Taunton and Somerset Hospital, Musgrove Park, Taunton TA1 5DA, UK

Correspondence to: Dr Paul Lambert

E-mail: Paul.Lambert@tst.nhs.uk

\section{COMMENT}

Acute renal failure and interstitial nephritis are well documented adverse effects of non-steroidal anti-inflammatory drugs. However, we have found only two reports of effects of these drugs on renal tubular acidification. In both, overdose of ibuprofen was reported as causing type 2 proximal renal tubular acidosis. ${ }^{2,3} \mathrm{We}$ believe this is an important issue to raise, because in the present case and that of Chetty et al. ${ }^{3}$ the ibuprofen was an over-the-counter preparation. Abuse of such agents can easily escape notice.

Acknowledgment We thank Dr RE Ferner (West Midlands Centre for Adverse Drug Reporting, City Hospital, Birmingham B18 7QH, UK) for his help in the preparation of this report.

\section{REFERENCES}

1 British Medical Association, Royal Pharmaceutical Society of Great Britain. British National Formulary. London: BMA/RPS, 2003:479-81

2 Gaul C, Heckmann JG, Druschky A, Schocklmann H, Naundorfer I, Erbguth F. Renal tubular acidosis with severe hypokalemic tetraparesis after ibuprofen intake. Dtsch Med Wochenschr 1999;124:483-6

3 Chetty R, Baoku Y, Mildner R, Banerjee A, Vallance D, Haddon A, Labib M. Severe hypokalemia and weakness due to Nurofen ${ }^{\circledR}$ misuse. Ann Clin Biochem 2003;40:422-3

\section{Myocardial infarction after aspirin treatment}

\section{David J Fox MB MRCP Timothy P Gray MB MRCP \\ Farzin Fath-Ordoubadi MD MRCP}

J R Soc Med 2005;98:21-23

Aspirin has been reported to cause coronary spasm as well as bronchospasm, but never acute myocardial infarction.

\section{CASE HISTORY}

A woman of 55 attended the emergency department after six hours of left-sided chest pain. She was a smoker. Previously she had been fit and well apart from mild asthma. There was no history of illicit drug use. She did report an 'allergy' to aspirin but was vague about how this showed itself. On examination she was haemodynamically stable and the only finding of note was mild expiratory

Manchester Heart Centre, Manchester Royal Infirmary, Oxford Road, Manchester M13 9WL, UK

Correspondence to: Dr David Fox

E-mail: david.j.fox@talk21.com 


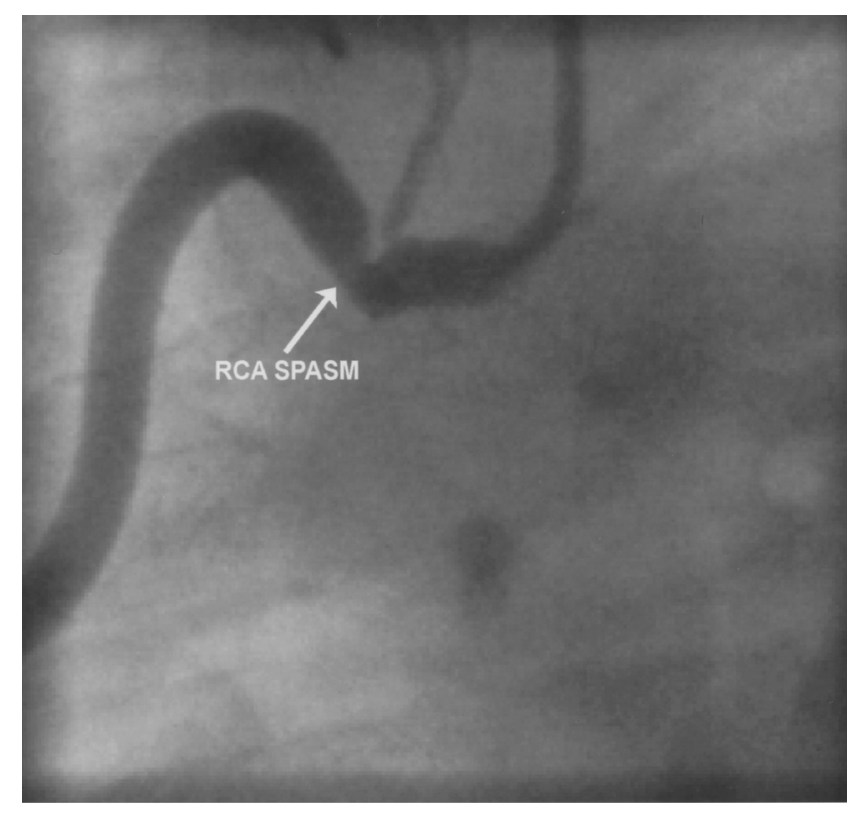

Figure 1 Proximal spasm in right coronary artery

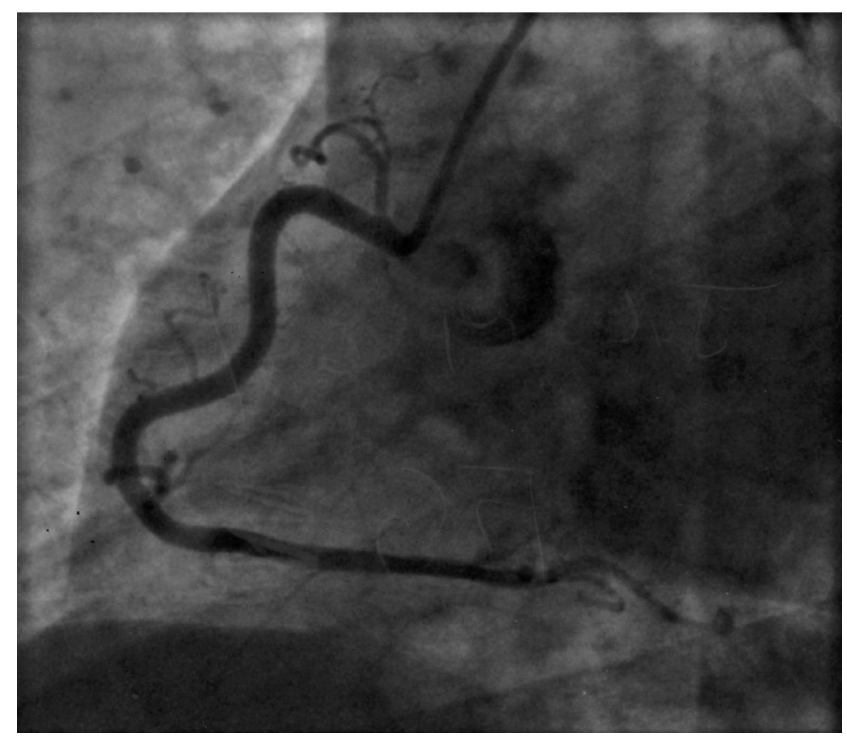

Figure 2 Right coronary artery after intracoronary nitrate

wheeze. Baseline investigations including oxygen saturations and cardiac enzymes gave normal results; cholesterol was $4.8 \mathrm{mmol} / \mathrm{L}$. Serial 12-lead electrocardiograms showed sinus rhythm and no evidence of ischaemia.

She was initially managed with oxygen and sublingual glyceryl trinitrate, and when this made no difference to her pain she was given intravenous diamorphine. After 10-15 minutes her symptoms had improved but as a precautionary measure the emergency team decided to administer $300 \mathrm{mg}$ aspirin. In the next 20 minutes a florid urticarial rash developed over the patient's entire body surface, she became breathless and she reported central crushing chest segment elevation of up to $7 \mathrm{~mm}$ with associated complete heart block and she was transferred for coronary angiography. Premedication was $200 \mathrm{mg}$ intravenous hydrocortisone and $10 \mathrm{mg}$ chlorphenamine. Gross vasospasm was seen in the left and the right coronary arteries, particularly near the ostium of the right coronary artery (Figure 1). This abated with intracoronary nitrate injections and at the end of the procedure all the arteries appeared normal (Figure 2). Intravascular ultrasound examination of the left and right coronary artery revealed no evidence of atheromatous plaque. She settled on nitrate and calcium channel blocker therapy but measurements of troponin $\mathrm{T}$ $(0.22 \mu \mathrm{mol} / \mathrm{L})$ and creatine kinase $1337 \mathrm{u} / \mathrm{L}$ twelve hours after the procedure indicated myocardial damage. On echocardiography, inferior hypokinesia was consistent with infarction in the right coronary artery territory. She recovered without incident and was discharged after five days taking the antiplatelet agent clopidogrel. While she was in hospital, relatives provided some information about her aspirin allergy: she had developed a serious rash and been very unwell after taking aspirin in the past.

\section{COMMENT}

We postulate that the coronary vasospasm and infarction resulted from the aspirin administration. After aspirin, her atypical pain changed to a typical crushing cardiac chest pain, and ischaemic changes developed on the electrocardiogram. Possible mechanisms are coronary artery smooth muscle spasm ${ }^{1}$ or massive catecholamine release as part of a stress response to the adverse drug reaction. Aspirin-induced coronary vasospasm has been reported previously, leading to exercise induced angina. ${ }^{2}$ Also, variant angina has been suggested to be aggravated by aspirin. ${ }^{3}$ In our patient the pain on admission was probably musculoskeletal; there was no evidence of cardiac ischaemia at that time.

There is only one previous report of coronary spasm related to asthma ${ }^{4}$, and in this the authors suggest a link between bronchospasm and coronary spasm caused by aspirin. With cocaine, spasm leading to myocardial infarction is well recognized ${ }^{5}$ but we have found no recorded case of aspirin inducing spasm severe enough to cause infarction. Patients who are suspected of having ischaemic chest pain and who report allergy to aspirin should be given an alternative antiplatelet agent such as clopidogrel.

\section{REFERENCES}

1 Ramanuja S, Breall JA, Kalaria VG. Approach to 'aspirin allergy' in cardiovascular patients. Circulation 2004;110:e1-e4

2 Miwa K, Kambara H, Kawai C. Exercise-induced angina provoked by aspirin administration in patients with variant angina. Am $J$ Cardiol 1981;47:1210-14 
3 Miwa K, Kambara H, Kawai C. Variant angina aggravated by aspirin. Lancet 1979;2:1382

4 Habbab MA, Szwed SA, Haft JI. Is coronary arterial spasm part of the aspirin-induced asthma syndrome? Chest 1986;90:141-3

5 Kontos MC, Jesse RL, Tatum JL, Ornato JP. Coronary angiographic findings in patients with cocaine-induced chest pain. J Emerg Med 2003;24:9-13

\section{Splenomegaly, anaemia and pleural effusion}

\author{
P Kojodjojo MRCP S Chew BSc \\ $\mathrm{K}$ Wakeham BSc MRCP R Lancaster FRCP
}

J R Soc Med 2005;98:23-24

Most pseudocysts of the spleen cause no symptoms, but occasionally they lead to disaster.

\section{CASE HISTORY}

A man of 71 was admitted after syncope. He was on treatment for hypertension, atenolol $25 \mathrm{mg}$ daily, with good control. Recently he had lost a few kilograms but had otherwise been fit and well. He had not travelled abroad for many years and was teetotal.

His blood pressure was $133 / 76 \mathrm{mmHg}$ without postural drop, pulse $78 / \mathrm{min}$. On chest examination there was a small area of stony dullness at the left base, consistent with a small pleural effusion; the abdomen was distended and a very large spleen could be felt. Investigations revealed a normochromic normocytic anaemia (haemoglobin $10.3 \mathrm{~g} /$ $\mathrm{dL})$, white cell count $13.7 \times 10^{9} / \mathrm{L}$ (81\% neutrophils, $17 \%$ lymphocytes) and platelets $307 \times 10^{9} / \mathrm{L}$. Liver function tests, corrected calcium and clotting profile were normal. Blunting of the left costophrenic angle was seen on a chest radiograph, in keeping with the positive respiratory findings. Further investigations were requested including serum electrophoresis, hepatic screen, abdominal imaging and bone marrow studies.

Several hours later the patient experienced presyncope on the ward and blood pressure declined to $97 / 62 \mathrm{mmHg}$, pulse $74 / \mathrm{min}$. Clinically, the left-sided pleural effusion was larger and the haemoglobin was now $8.1 \mathrm{~g} / \mathrm{dL}$. The abdomen remained non-tender and the size of the spleen had not obviously changed. A diagnostic pleural tap drew a

Department of General Medicine, St Mary's Hospital, London W2 1NY, UK Correspondence to: Pipin Kojodjojo, Waller Department of Cardiology, St Mary's Hospital, Praed Street, London W2 1NY, UK

E-mail: pipin.kojodjojo@imperial.ac.uk

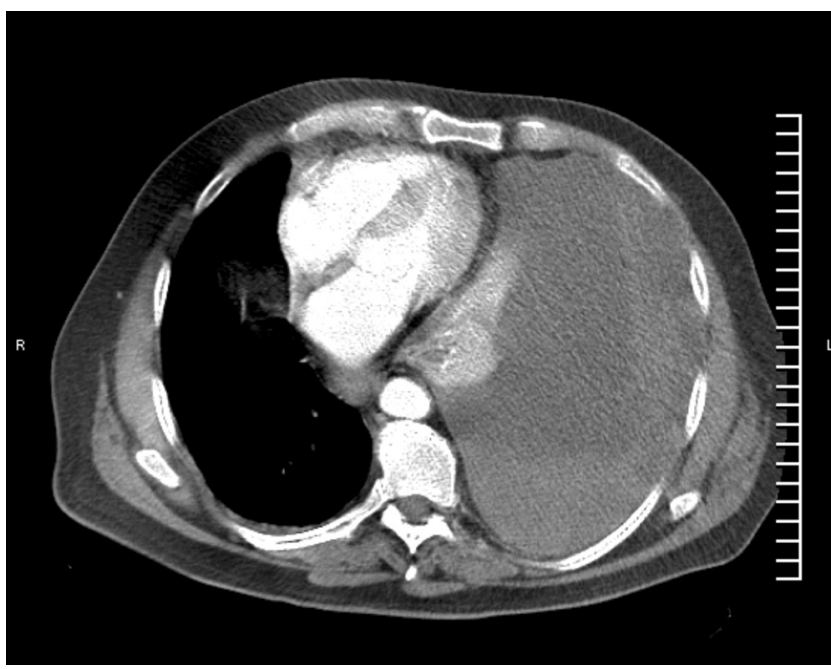

Figure 1 CT of chest showing large left pleural effusion around the collapsed lung (black arrow) with associated mediastinal shift

small amount of dark blood. Central venous and urinary catheters, along with an arterial line, were inserted to monitor his haemodynamic status more closely. CT showed a large effusion almost completely filling the left hemithorax, associated with complete left lung collapse and mediastinal shift (Figure 1). The spleen was massively enlarged, measuring $23 \times 23 \times 17 \mathrm{~cm}$ - a cyst with only a thin rim of splenic tissue (Figure 2). No rib fractures, other bony injuries or lymphadenopathy were seen.

His blood pressure responded to blood and colloid transfusions, but before he could be transferred for exploratory thoracolaparotomy he had a cardiac arrest. After restoration of the pulse and fluid administration, insertion of an intercostal drain yielded $3 \mathrm{~L}$ of dark altered blood. At operation he was found to have a splenothoracic fistula. There was no blood in the peritoneal cavity. The spleen was removed and the left diaphragm was repaired.

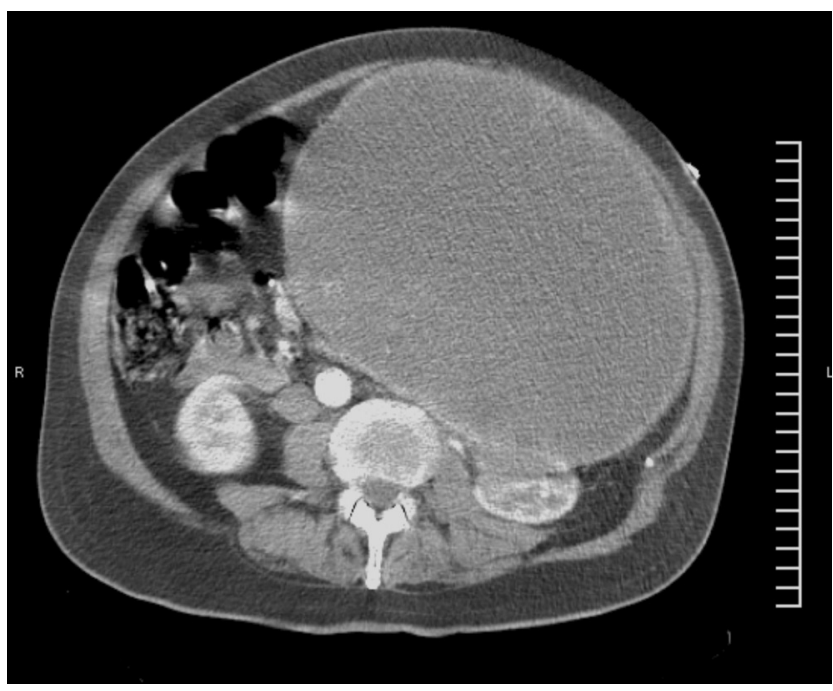

Figure $2 \mathbf{C T}$ of abdomen showing thin rim of splenic tissue encasing cyst 